\title{
Studies on the Conjugated Lipids
}

\section{Part XIII. Configuration of Sphingomyelin}

Sir:

The chemical structure of sphingomyelin has recently been established by Fujino ${ }^{13}$ and by Rouser et al..2) as follows :

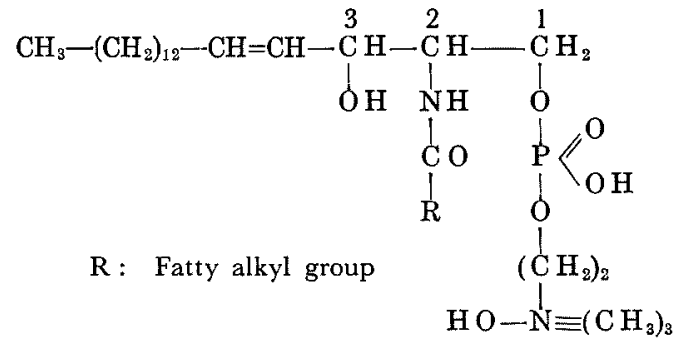

In this structural formula, the configurational establishment is concerned with the two asymmetric carbon atoms and the double bond of the sphingosine moiety. Since it has been verified that the amino carbon atom has the D configuration ${ }^{3)}$ and the double bond has the trans configuration ${ }^{4}$, the pending point is that whether the configuration of carbon atom number three is erythro or threo.

In solving this problem, it seemed pertinent to investigate the configuration of sphingosine, which is usually obtained from acid hydrolysis of sphingolipide. The procedure, however, gives a mixture of the erythro and the threo bases $^{5,6)}$, probably because inversion of the configuration occurs in the course of hydrolysis, owing either to the activity of an allylic hydroxyl group at the second asymmetric centre in the molecule ${ }^{6,7,8)}$, or to the $\mathrm{N} \rightarrow \mathrm{O}$

1) Y. Fujino, J. Biochem., 39, 45 (1952).

2) G. Rouser, J.F. Berry, G. Marinetti and E. Stotz, J. Am. Cbem. Soc., 75, 310 (1953)

3) H.E. Carter and C.G. Humiston, J. Biol. Cbem., 191, 727 (1951).

4) G. Marinetti and E. Stotz, J. Am. Chem. Soc, 76, 1347 (1954).

5) P.V. Seydel, Zur Kenntnis des Sphingosins, Diss., ETH. Zurich (1941); C.A. Grob and E. F. Jenny, Helv. Chim. Acta, 35, 2106 (1952).

6) H.E. Carter, O. Nalvandov and P.A. Tavormina, J. Biol. Chem., 192, 197 (1951). migration of the acyl group in such an amino alcohol compound as sphingolipide ${ }^{7,9,10)}$. The author previously reported, in the meantime, a hydrolytic procedure ${ }^{7,10)}$ which gave no stereoisomerisation at carbon atom number three in the molecule of cerebroside, a kind of sphingolipide. Thus it was decided to apply the same procedure for hydrolysis of sphingomyelin to obtain only one isomer of sphingosine.

A pure preparation of sphingomyelin ${ }^{11}$, prepared from crude sphingolipide of beef brain, was hydrolyzed with a saturated solution of barium hydroxide in dioxane-water $(1: 1)$ to give sphingosine-phosphorylcholine (sphingosine phosphate in part). The product was hydrogenated and the saturated material was subjected to hydrolysis with $1.6 \mathrm{~N}$ ethanolic solution of hydrochloric acid. Dihydrosphingosine was obtained in a high yield (over 90\%) from the hydrolysate. The triacetyl and tribenzoyl derivatives of the compound were characterized and compared with those of the synthetic bases ${ }^{12}$. Thus, the natural dihydrosphingosine was proved to be

$\begin{array}{lcc} & \text { TABLE I } & \\ \text { Dihydrosphingosine } & \text { Triacetyl- } & \text { Tribenzoyl- } \\ \text { mp. }{ }^{\circ} \mathrm{C} & \text { mp. }{ }^{\circ} \mathrm{C} \\ \begin{array}{l}\text { Synthetic erythro- } \\ \text { Synthetic threo- }\end{array} & 98-100 & 144-145 \\ & 46 & - \\ \begin{array}{l}\text { Natural, obtained } \\ \text { from sphingomyelin }\end{array} & 100-101 & \text { (only dibenzoyl) }\end{array}$

7) Y. Fujino and H.E. Carter, Proceedings of the IInd International Conference on Biochemical Problems of Lipids, p. 115, Butterworths Scientific Publications, London (1955).

8) Y. Fujino, J. Agr. Chem. Soc. (in Japanese) , 31, 46 (1957)

9) L.H. Welsh, J. Am. Chem. Soc., 71, 3500 (1949).

10) H.E. Carter and Y. Fujino, J. Biol. Cbem., 221, 879 (1956)

11) Y. Fujino and T. Negishi, Unpublished.

12) H.E. Carter, D. Shapiro and J.B. Harrison, J. Am. Chem. Soc, 75, 1007 (1953). 
identical with the synthetic erythro base as shown in Table I. No threo isomer could be found in the hydrolysis product. These data establish that sphingomyelin has the erythro configuration in the sphingosine moiety of the molecule, as in the case of cerebroside ${ }^{7,10)}$

The author wishes to express his sincere thanks to Prof. Y. Nakamura and Prof. Y. Obata of Hokkaido University for their kind advice and revisions.

Department of Dairy Science

Yasuhiko FuJino

Obihiro Zootechnical College, Obihiro

Received August 16, 1958

[Bull. Agr. Chem. Soc. Japan, Vol. 22, No. 6, p. 427 428, 1958]

\section{The Absolute Configuration of Naturally Derived Pyrethrolone and Cinerolone}

Sir :

A sole remaining important problem in the field of pyrethrum chemistry is the elucidation of the absolute configuration of naturally derived pyrethrolone and cinerolone.

However, hitherto little is known concerning the stereochemistry of the hydroxyl group of these cyclopentenolones although an extreme ease of racemization has been observed and the fact that both alcohols are alike in dextrorotation suggests that they belong to the same stereochemical series.

As it has been shown in the preliminary study ${ }^{1)}$, recemic allethrolonemethylether afforded $\alpha$-methoxysuccinic acid in the sequel of oxidative degradations. In a like manner the dextrorotatory methylethers of naturally derived pyrethrolone and cinerolone were subjected to stepwise oxidations. Thus, $(+)-$ pyrethrolonemethylether (II-a), b.p. 95-6\% $/ 1.5$ mm., $[\alpha]_{D}^{26}+10.5^{\circ}$, was at first ozonised to yield, in addition to neutral products, a complex mixture of acid having a laevorotation of $[\alpha]_{D}$ ca. $-5^{\circ}$ After the removal of volatile and ether-insoluble acids, the optically active acid fraction mainly consisted of the ketoacid of the structure (III), which, though not isolated pure, was shown by the positive reactions against carbonyl reagents as well as by the formation of bromoform in the subsequent

1) Y. Katsuda, T. Chikamoto and Y. Inouye, This Bulletin 23, in press. hypobromite oxidation. The potassium hypobromite oxidation of the crude keto-acid gave (-)- $\alpha$-methoxysuccinic acid (V), m.p. 89-91 ${ }^{\circ}$, $[\alpha]_{\mathrm{D}}^{27}-25.0^{\circ}$, (Anal. Found. C, 40.73; H, 5.61; Calcd. for $\mathrm{C}_{5} \mathrm{H}_{8} \mathrm{O}_{5}, \mathrm{C}, 40.54 ; \mathrm{H}, 5.44$ ), equivalent weight by titration Found, 73.80 Calcd. for $\mathrm{C}_{3} \mathrm{H}_{6} \mathrm{O}\left(\mathrm{CO}_{2} \mathrm{H}\right)_{2}, 74.05$. Judging from the manner of consumption of hypobromite, it seems likely that the oxidation proceeds through the intermediate (-)- $\alpha$-methoxy- $-\alpha^{\prime}-$ ketoglutaric acid (IV).

(+)-Cinerolone-methylether (II-b), b.p. 91$2^{\circ} / 1.2 \mathrm{~mm}$., $[\alpha]_{\mathrm{D}}^{36}+10.0^{\circ}$, also afforded (-)$\alpha$-methoxysuccinic acid (V), m.p. $89-92^{\circ}$, $[\alpha]_{\mathrm{D}}^{97}-24.6^{\circ}$, in exactly the same sequel of oxidations.

It is recorded in the literature ${ }^{2)}$ that optically pure laevorotatory $\alpha$-methoxysuccinic acid melts at $88-9^{\circ}$ and has a rotation $-58.18^{\circ}$ in acetone at $13^{\circ}$ In spite of the slight discrepancies of these physical properties the observed between the present authors' samples and those in the literature, which might be ascribed to a partial racemization during the processes, the identity was evidenced by analyses and equivalent weight which were in agreement with the theoretical, as well as by infra-red spectrum indicating the necessary absorptions of its functions. Not to mention, it could be nothing else but $\alpha$-methoxysuc-

2) Purdie and W. Marshall, J. Chem. Soc., 63, 218 (1893). 